\section{Re: Trends in Physician House Calls to Medicare Beneficiaries}

To the Editor: What stood out most in this important and informative article ${ }^{1}$ was that while the number of home visits by physicians doubled between 2000 and 2006, family medicine (FM) physicians showed the smallest increase compared with other physicians. This is despite the fact that the top 5 billed diagnoses are conditions that are easily managed by FM physicians: hypertension, congestive heart failure, diabetes, COPD, and Alzheimer's disease. Moreover, physicians making home visits are growing older in age.

This suggests that although there is growing societal need for home visits, we are not educating a new generation of FM physicians to confidently practice in the patient's home. The Residency Review Committee (RRC) of the Accreditation Council for Graduate Medical Education (ACGME) requires FM residents to complete a mere 2 home visits during residency. ${ }^{2}$ This is not a sufficient number to build competence, much less proficiency in anything. Moreover, it is currently not uncommon for residency programs to lack formal, structured instruction and training on home visits. An online search via Google and PubMed does not yield any articles mentioning home visit curricula for FM residents, except for a letter to the editor in Family Medicine from $2006^{3}$ and a mention in Canadian Family Physician dated from $1996 .^{4}$

FM residents need to be deliberately and specifically taught the necessary skills to competently perform effective home visits so that they see the value of home visits and experience the satisfaction they can bring, both to the patients and the physician. They should be learning how to manage an interdisciplinary team to help take care of patients at home. A structured curriculum with clear learning objectives and direct experiences using a practical model should be part of FM residency. By making it a natural part of their training, FM residents will be able to incorporate them more efficiently and effectively after they graduate. More importantly, society will benefit from a multilayered social support system that enables patients, especially elderly ones, to live independently with an emphasis on maintaining a high quality of life.

Tomoko Sairenji, MD

Department of Family Medicine University of Pittsburgh

Pittsburgh, PA

sairenjit@upmc.edu

\section{References}

1. Peterson LE, Landers SH, Bazemore A. Trends in physician house calls to Medicare beneficiaries. J Am Board Fam Med 2012;25:862-8.
2. ACGME program requirements for graduate medical education in family medicine. Effective July 1, 2007. Available from: http://www.acgme.org/acgmeweb/Portals/0/ PFAssets/ProgramRequirements/120pr07012007.pdf. Accessed November 8, 2013.

3. Hseih C. Family medicine residents and home visits. Fam Med 2006;38:691-2.

4. Boillat M, Boulet S, De Courval L. Teaching home care to family medicine residents. Can Fam Physician 1996;42: 281-6.

doi: 10.3122/jabfm.2014.01.130261

The above letter was referred to the author of the article in question, who offers the following reply.

\section{Response: Re: Trends in Physician House Calls to Medicare Beneficiaries}

To the Editor: As a relatively recent family medicine residency graduate, I experienced firsthand how the Accreditation Council for Graduate Medical Education's (ACGME) requirement of 2 house calls was usually fulfilled. I and most of my fellow residents made our house calls late in our third year, and the training consisted of being told where the "house call bag" was and to make sure we documented the visit. This was certainly not sufficient preparation for incorporating house calls into practice but rather "checking the box" so as to not incur ACGME citations. I agree with the author that a national house call curriculum for family medicine residencies would be a wonderful resource. There seemed to be momentum for strengthening geriatric training in family medicine when, 10 years ago, Family Medicine published 4 articles on the state of geriatrics training. ${ }^{1-4}$ Overall conclusions from these studies were that the Residency Review Committee's downgrading of geriatrics training requirements from "must" to "should" were met with the expected responses of deemphasizing geriatrics education. Barriers to geriatric education, not to mention house calls, include limited geriatric faculty and competing curricular demands.

Others have commented on the contrast between strict obstetrical educational requirements in residency, despite few graduates providing this service after graduation, and loose geriatric requirements despite the fact that nearly all graduates will care for the elderly. ${ }^{3}$ This holds true today; my own preliminary analyses of nearly 8000 physicians' responses to the practice demographic survey completed during registration for the American Board of Family medicine 2013 spring recertification examination found that $21.8 \%$ provided home visits, $91.8 \%$ saw patients older than 75 years of age, and $9.1 \%$ performed obstetrical deliveries.

The need for house calls will only increase in the future because of a growing population of elderly pa- 